\title{
Diospyrobezoar as a Cause of Small Bowel Obstruction
}

\author{
Andréia Padilha de Toledo ${ }^{a}$ Fernanda Hurtado Rodrigues ${ }^{a}$ \\ Murilo Rocha Rodrigues $^{a}$ Daniela Tiemi Sato ${ }^{a}$ Ronaldo Nonose $^{b}$ \\ Enzo Fabrício Nascimento ${ }^{\mathrm{b}}$ Carlos Augusto Real Martinez ${ }^{\mathrm{b}}$ \\ ${ }^{a}$ São Francisco University Medical School and ${ }^{b}$ Department of General Surgery \\ of São Francisco University Hospital, Bragança Paulista, Brazil
}

\section{Key Words}

Bezoars · Diospyros kaki · Persimmon · Intestinal obstruction · Operative surgical procedure

\begin{abstract}
Phytobezoar, a concretion of indigestible fibers derived from ingested vegetables and fruits, is the most common type of bezoar. Diospyrobezoar is a subtype of phytobezoar formed after excessive intake of persimmons (Diospyros kaki). We report the case of a diabetic man with a 5-day history of abdominal pain after massive ingestion of persimmons who developed signs of complicated small bowel obstruction. The patient had a previous history of Billroth II hemigastrectomy associated with truncal vagotomy to treat a chronic duodenal ulcer 14 years earlier. Since intestinal obstruction was suspected, he underwent emergency laparotomy that revealed an ileal obstruction with small bowel perforation and local peritonitis due to a phytobezoar that was impacted $15 \mathrm{~cm}$ above the ileocecal valve. After segmental intestinal resection, the patient had a good recovery and was discharged on the 6th postoperative day. This report provides evidence that diospyrobezoar should be considered as a possible cause of small bowel obstruction in patients who have previously undergone gastric surgery.
\end{abstract}

\section{Introduction}

Bezoars are concretions or hard masses of foreign matter that are found in the gastrointestinal tract. The word 'bezoar' derives either from the Arabic term 'badzehr' or the Persian word 'padzahr', both of which denote counterpoison or antidote [1]. This condition was described for the first time during the autopsy of a patient who died from gastric perforation and peritonitis [2]. The presence of a bezoar in the gastrointestinal tract is rare, with an estimated incidence of $<1 \%$ in the general 
population [3, 4]. Bezoars can be classified into four principal types according to their main constituents: trichobezoars, lactobezoars, pharmacobezoars and phytobezoars [5].

Phytobezoars are the most common type of bezoars found in the alimentary tract and are formed of food fibers indigestible by humans (cellulose, hemicellulose, lignin and fruit tannins) frequently founded in grape skin, pineapple, prune and persimmons (Diospyros kaki) [6-8]. They more frequently occur in patients who have dentition problems, impaired digestion, patients subjected to gastric surgery or with clinical conditions that delay gastric emptying [8]. Other predisposing factors are overindulgent ingestion of high-fiber foods, abnormal chewing and diminished gastric secretion, neuropathy in diabetic patients, hypothyroidism and myotonic dystrophy. Phytobezoar causing small bowel obstruction in patients with previous gastric surgery is well known as a late complication, although very rare. The incidence of postgastrectomy bezoar ranges between 5 and $12 \%$ and phytobezoars represents the 5th most common cause of acute small bowel obstruction accounting for only $0.4-4.8 \%$ of all cases of intestinal obstruction $[9,10]$.

Diospyrobezoars are a phytobezoar subtype formed after massive ingestion of persimmons [11]. They are formed by the agglutination of the tannins in the skin of the fruit that forms a glue-like coagulum after contact with dilute acid in the stomach $[3,11,12]$. Although diospyrobezoar is one of the most common subtypes of phytobezoar, its true incidence remains unknown. In a careful review of the PubMed/Medline database, to the best of our knowledge, less than 90 cases have been well documented in the worldwide literature.

The aim of this study is to report a rare case of intestinal obstruction caused by massive ingestion of persimmons in a patient who had undergone hemigastrectomy and associated truncal vagotomy to treat a chronic duodenal ulcer 14 years earlier, and to discuss the main aspects related to symptoms, diagnosis and treatment.

\section{Case Report}

A 66-year-old diabetic man was referred to our center for further management of an intestinal obstruction. He presented with a 5-day history of abdominal pain associated with nausea and abdominal distension, which was worst with food ingestion. His bowel habits were mildly altered, but there was no history of blood per rectum. He denied any loss of weight or appetite. His past surgical history consisted of a Billroth II partial hemigastrectomy associated with a truncal vagotomy to treat a chronic duodenal ulcer 14 years earlier. During admission, the patient's pain increased in intensity and was accompanied by stasis, vomiting as well as cessation of flatus and bowel movements. He also had a 6-day history of excessive persimmon ingestion. On physical examination, the patient was dehydrated with a blood pressure of $100 / 90 \mathrm{~mm} \mathrm{Hg}$ and a heart rate of 120 beats/min. His abdomen was distended and painful on diffuse palpation with signs of peritoneal irritation. Bowel sounds were sluggish, and rectal examination revealed an empty rectum with no palpable mass. Abnormal laboratory values included a white blood cell count of $13.3 \times 10^{3}$ cells $/ \mu \mathrm{l}$, a glucose level of $190 \mathrm{mg} / \mathrm{dl}$, a urea level of $225 \mathrm{mg} / \mathrm{dl}$ and a creatinine level of $3.5 \mathrm{mg} / \mathrm{dl}$. A radiograph of the abdomen revealed two significantly dilated small bowel loops with gas-fluid levels and fold thickening in the left side of the abdomen. A clinical diagnosis of intestinal obstruction was then made based on the radiologic findings.

After the fluid and electrolyte disturbances had been corrected, an exploratory laparotomy was performed which revealed severe adhesive disease that required extensive lysis of adhesions. His jejunum and ileum were dilated and hypertrophied, and a cylindrical bezoar was found $15 \mathrm{~cm}$ from 
the ileocecal valve. At the site of bezoar impaction, a $3 \mathrm{~mm}$ bowel perforation with drainage of intestinal contents and focal peritonitis was identified (fig. 1). A resection of $15 \mathrm{~cm}$ of small bowel above the ileocecal valve was performed, which removed the entire area containing the phytobezoar and perforation. Intestinal transit was reconstituted by a single-layer end-to-end ileoileal anastomosis with monofilament absorbable stitches. Inside the removed intestinal segment, a brownish phytobezoar measuring $12 \times 5 \mathrm{~cm}$ and weighing $40 \mathrm{~g}$ was identified (ig. 2 ).

At the surface of the ileal mucosa, it was possible to identify a large, deep ulceration that was $3 \mathrm{~cm}$ in diameter and surrounded the site of the perforation. The pathology report for the operative specimen was degenerate vegetable matter and a benign ischemic ileal ulcer associated with peritonitis. The postoperative period was uneventful; the patient was started on nourishing fluid and a soft diet and was discharged 6 days later. After 1 year, he was found to be well during a follow-up surgical clinic visit, and he was properly oriented with respect to the risks of eating fruits and vegetables capable of forming phytobezoars.

\section{Discussion}

Bezoars are composed of ingested foreign materials that accumulate within the gastrointestinal tract [7]. They are named according to the substance of which they are composed. The common types of bezoars are as follows: phytobezoars (indigestible food fibers), pharmacobezoars (composed of undigested medications), trichobezoars (composed of hair and most commonly found in young women affected by trichotillomania), tricholithobezoars (composed of hair and bile salts), lactobezoars (composed of ingested milk), and foreign body bezoars (composed of chewing gum, drugs, coins and other types of iron or plastic materials) [5, 6, 13, 14]. Phytobezoars are the most common type; they are composed of vegetable matter and contain a large amount of indigestible fibers such as cellulose, hemicellulose, lignin and fruit tannins [4].

Reports of bezoars causing obstruction of the gastrointestinal tract can be found dating back to the late 18th century [15]. Phytobezoars causing obstruction of the small intestine after gastrectomy was first reported by Seifert in 1930, and since then, an increasing number of cases have been described. The true incidence of intestinal obstruction caused by phytobezoars is still not well understood. In 2010 Yakan et al. [12], studying 432 cases of small bowel obstruction treated within 10 years, found that only 14 cases (3.2\%) were caused by phytobezoars. A recent meta-analysis of 19 studies published between 1994 and 2005 showed that out of 996 cases of acute small bowel obstruction, 8 were due to a bezoar of the small bowel $(0.8 \%$ of all etiologies). This makes bezoars the fifth most frequent cause of acute small bowel obstructions after adhesion (83.2\%), external hernia (3.1\%), malignancy (2.9\%) and internal hernia (1.9\%) [16].

Diospyrobezoar is a subtype of phytobezoar caused by ingestion of persimmons (Diospyros kaki), and although it can occur anywhere in the world, it is described more frequently in temperate and subtropical regions [17]. Krausz et al. [18] reported a huge increase in the incidence of phytobezoar obstruction in Israel which was related to the increasing availability and popularity of the persimmon fruit. In Hong Kong, the mid-autumn festival is celebrated in October and during this festival, it is a traditional to eat persimmon fruit [19]. Chisholm et al. [20] reported that two-thirds of the patients in their series presented around this festival time. Although phytobezoars are the most common type of bezoar, few studies have described the mechanism of 
formation of diospyrobezoars [18, 21]. Persimmon is a fruit that is rich in fiber and calories. Its pulp consists primarily of mucilage and pectin substances, which are responsible for the characteristic appearance of the fruit [18,22]. There is a high concentration of tannin (shiboul) that can precipitate when in contact with gastric juice. In the presence of the dilute hydrochloric acid inside the stomach, the tannin undergoes polymerization to form a coagulum that includes cellulose, hemicellulose and protein that is the basis of the bezoar [22]. Subsequently, this cluster undergoes dehydration, being more consistent due to kinetic energy provided by the gastric wall. This contributes to the formation of the diospyrobezoar.

In most cases, diospyrobezoar formation is associated with previous gastric surgery (truncal or selective vagotomy plus pyloroplasty or subtotal gastrectomy plus gastroenterostomy), dental problems leading to poor mastication, vegetarian diet and excessive consumption of persimmons $[8,11]$. Postoperative adhesions are also predisposing factors for bezoar formation [4]. A recent study showed that the main predisposing factors were previous gastric surgery in $87.5 \%$ and previous abdominal surgery and total absence of the teeth in $14.3 \%$ of patients [12]. Truncal or selective vagotomy may reduce gastric motor activity and delay gastric emptying, which favors the formation of different types of bezoars. Loss of pyloric function, stenosis of the pylorus as occurs in chronic duodenal ulcers, gastric motility and hypoacidity also play an important role in the formation of diospyrobezoars [23]. The increasing number of gastric bypass surgeries for the treatment of morbid obesity has also contributed to the increase in cases of intestinal obstruction by phytobezoars [24]. A study involving 117 patients with gastrointestinal bezoars revealed that $87 \%$ occurred in the small bowel. Furthermore, $70 \%$ of patients had previous surgery for peptic ulcer disease, and $80 \%$ of these patients had a bilateral truncal vagotomy with pyloroplasty [25]. Systemic diseases such as diabetes mellitus and hypothyroidism have also been reported as predisposing factors for diospyrobezoar formation because they delay gastric emptying [26]. Similarly, our patient had a previous history of diabetes and a hemigastrectomy with trunk vagotomy 14 years previously to treat a duodenal ulcer that was refractory to medical treatment. He had also recently consumed 12 persimmons. These factors led to a preoperative suspicion of intestinal obstruction due to diospyrobezoar.

Clinical manifestations can vary depending on the location of the bezoar in the gastrointestinal tract, from no symptoms to acute abdominal syndrome. Abdominal pain (49-100\%), epigastric distress (80\%), anorexia, vomiting and nausea (35-78\%), and small bowel obstruction (94.73\%) are the main clinical symptoms [11]. The preoperative diagnosis of small bowel obstruction due to diospyrobezoar is difficult, given that these patients often have a history of gastric surgery or, at the very least, of a previous laparotomy [12]. In these situations, the initial diagnosis is often adhesive obstruction. A study showed that when the patients had small bowel obstruction, severe nausea and vomiting were present in $100 \%$ of cases and physical examination identified signs of acute obstruction in all patients who presented with fecal vomiting and abdominal tenderness [12]. The most common site of phytobezoar formation is the stomach, where it often generates gastric ulcers. However, it is usual to find some phytobezoars in the small bowel, particularly in the jejunum and proximal ileum, where they can become impacted and cause luminal obstruction [17]. Major complications of diospyrobezoars located in the small bowel can include gastrointestinal bleeding due to 
ischemic ulceration of the intestinal mucosa and intestinal perforation with peritonitis, as occurred with the patient in this report [4].

Preoperative plain abdominal radiography and ultrasonographic examination were nonspecific and inconclusive in most patients [12]. Sometimes, plain abdominal films can reveal dilated small bowel loops with air-fluid levels $[6,9]$. When there is intestinal perforation, as in the current patient, it is possible to identify a pneumoperitoneum. In this patient, it is possible that we could not identify the presence of pneumoperitoneum because the perforation was small and partially blocked by intestinal loops.

Ultrasonographic study is operator-dependent and visualization of the obstructive lesions may be hindered by overlying gas in the bowel [27]. In a retrospective study, ultrasound was able to detect phytobezoar in $88 \%$ of patients with intestinal obstruction [27]. Sometimes abdominal ultrasonography can suggest a hyperechoic arc-like surface and marked posterior acoustic shadowing of the bezoars within the intestinal lumen. Abdominal CT scan is the best diagnostic modality for detecting bezoars. CT scan has become the first-line examination for the evaluation of small bowel obstruction because it can exclude other causes of acute abdomen, differentiate between simple obstruction and strangulation, detect signs of concomitant intestinal ischemia, and accurately define the cause, degree and level of obstruction [12]. Pathognomonic signs include a well-defined ovoid intraluminal mass with mottled gas pattern at the site of obstruction, a focal transition zone with dilated fluid and air-filled loops of the small bowel proximally and collapsed loops of small bowel distal to the obstruction [28]. Evidence of a small bowel obstruction with dilated fluid and air-filled loops proximal to the obstruction and distal collapsed small bowel may also be present. Some authors also described the presence of target sign in $76 \%$ of their patients caused by edema or hemorrhage within the intestinal wall [29]. The presence of this sign on CT indicates that the phytobezoar obstructing the bowel may have difficulty in passing through the small bowel lumen.

The most important goal of treatment of intestinal obstruction due to diospyrobezoar is removal of the mass and prevention of recurrence [22]. Treatment of bezoars can be medical, surgical or endoscopic. Although medical treatment is often complementary to endoscopy, there have been published cases where it was successful on its own $[17,23,26]$. The pharmacologic approach includes everything from diet measures and the use of prokinetics to the enzymatic dissolution of the bezoar with agents such as cellulose, which shows the best results with an effectiveness of $83-100 \%$ [30]. Conservative management involves endoscopy and gastric lavage; however, diospyrobezoars are resistant to drug treatment and are more resistant than other phytobezoars. In 2002, Ladas et al. [31] reported the beneficial effects of the oral administration Coca-Cola ${ }^{\mathrm{TM}}$ based on the ability of this soft drink to dissolve phytobezoars, which is related to its active component, phosphoric acid, which maintains the $\mathrm{pH}$ at approximately 2.6. In addition, the bicarbonate content and the $\mathrm{CO}_{2}$ bubbles have mucolytic action. There are several publications describing the successful use of Coca-Cola ${ }^{\mathrm{TM}}$ in treating bezoars, in some cases after failure of endoscopic fragmentation and after failed dissolution by enzymatic drugs [30, 31]. However, it should be noted that the partial dissolution of bezoars located in the stomach can cause them to migrate to the small bowel, resulting in intestinal obstruction. 
If conservative treatment fails or complications develop, the bezoar should be surgically treated, ideally with laparoscopic approaches [31,32]. The laparoscopic approach is particularly useful in patients whose intestinal obstruction is diagnosed before lower bowel distension [31]. In the patient in this report, the time course of intestinal obstruction, clinical conditions, presence of peritonitis and great abdominal distension were decisive in the laparotomy approach. Although there are references to rates of intestinal obstruction recurrence due to phytobezoars, we believe that patients should be sufficiently informed about the pathogenic mechanisms of bezoar formation. As diospyrobezoar occurs mainly in patients undergoing gastric operations, such as the patient in this report, the possibility of recurrence should always be considered.

In conclusion, diospyrobezoar is an uncommon phytobezoar that can lead to intestinal obstruction. The best treatment for a diospyrobezoar is prevention based on good eating habits and oral hygiene, particularly in subjects with a history of gastric or abdominal surgery. This possibility should always be considered, especially in patients with a recent history of persimmon ingestion who have undergone previous gastric operations.

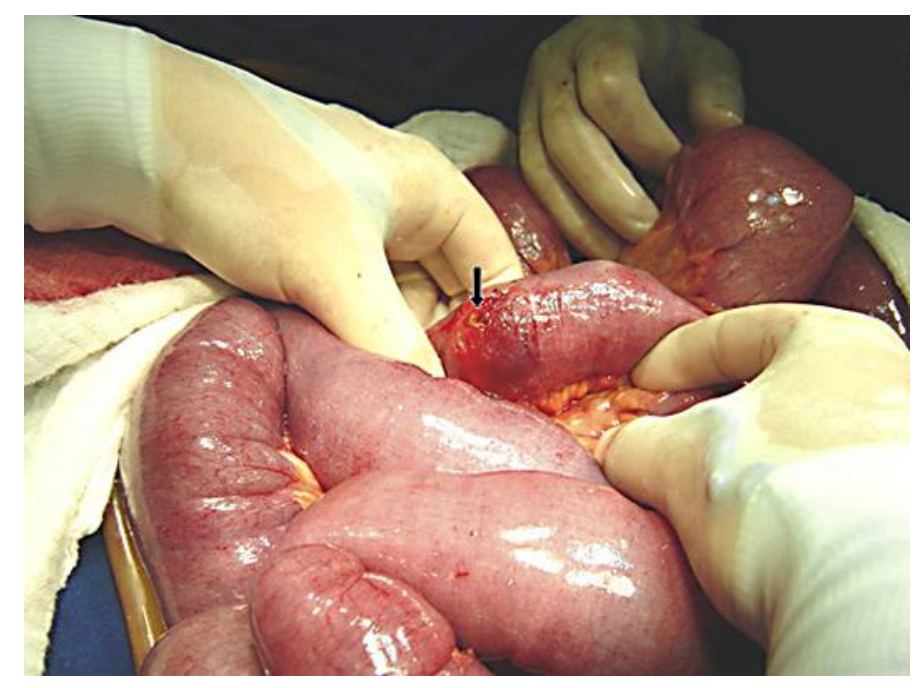

Fig. 1. Dilated small bowel loops due to ileal obstruction by a diospyrobezoar located $15 \mathrm{~cm}$ from the ileocecal valve. A small ileal antimesenteric perforation $3 \mathrm{~mm}$ in diameter (black arrow) was circumscribed by a $3 \mathrm{~cm}$ area of hyperemic inflammatory process. 


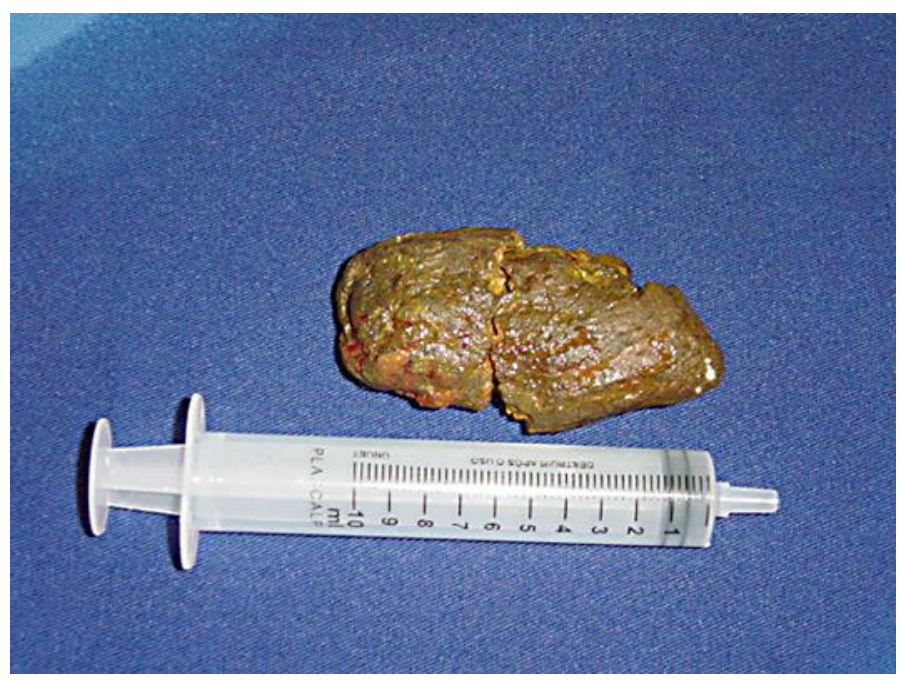

Fig. 2. Brownish diospyrobezoar divided into two parts, measuring $12 \times 5 \mathrm{~cm}$ and weighing $40 \mathrm{~g}$, removed from the distal ileum through a $15 \mathrm{~cm}$ enterectomy that included the site of ileal perforation.

\section{References}

1 Gonuguntla V, Joshi DD: Rapunzel syndrome: a comprehensive review of an unusual case of trichobezoar. Clin Med Res 2009;7:99-102.

2 Naik S, Gupta V, Naik S, Rangole A, Chaudhary AK, Jain P, Sharma AK: Rapunzel syndrome reviewed and redefined. Dig Surg 2007;24:157-161.

-3 Hewitt AN, Levine MS, Rubesin SE, Laufer I: Gastric bezoars: reassessment of clinical and radiographic findings in 19 patients. Br J Radiol 2009;82:901-907.

4 Sumskiene J, Janciauskas D, Pilkauskaite G, Kristalnyj V, Kupcinskas L: An unusual case of bleeding from stomach due to a giant diospyrobezoar. Medicina (Kaunas) 2009;45:476-479.

5 Santos Valenciano J, Nonose R, Bragattini Cruz R, Tiemi Sato D, Monteiro Fernandes F, Nascimento EF, Martinez CAR: Tricholithobezoar causing gastric perforation. Case Rep Gastroenterol 2012;6:26-32.

6 6 Ezat RF, Rashid SA, Rashid AT, Abdullah KM, Ahmed SM: Small intestinal obstruction due to phytobezoar: a case report. J Med Case Rep 2009;3:9312.

-7 Erzurumlu K, Malazgirt Z, Bektas A, Dervisoglu A, Polat C, Senyurek G, Yetim I, Ozkan K: Gastrointestinal bezoars: a retrospective analysis of 34 cases. World J Gastroenterol 2005;11:1813-1817.

8 Serour F, Dona G, Kaufman M, Weisberg D, Krispin M: Acute intestinal occlusion caused by phytobezoar in Israel. Role of oranges and persimmons. J Chir (Paris) 1985;122:299-304.

-9 Cifuentes Tebar J, Robles Campos R, Parrilla Paricio P, Lujan Mompean JA, Escamilla C, Liron Ruiz R, Pellicer Franco EM: Gastric surgery and bezoars. Dig Dis Sci 1992;37:1694-1696.

10 Acar T, Tuncal S, Aydin R: An unusual cause of gastrointestinal obstruction: bezoar. N Z Med J 2003;116: U422.

11 Zhang RL, Yang ZL, Fan BG: Huge gastric diospyrobezoar: a case report and review of literatures. World J Gastroenterol 2008;14:152-154.

12 Yakan S, Sirinocak A, Telciler KE, Tekeli MT, Deneçli AG: A rare cause of acute abdomen: small bowel obstruction due to phytobezoar. Ulus Travma Acil Cerrahi Derg 2010;16:459-463.

13 Nonose R, Valenciano JS, Lima JSS, Nascimento EF, Silva CMG, Martinez CAR: Jejunal diverticular perforation due to enterolith. Case Rep Gastroenterol 2011;5:445-451.

14 Lahan AY, Teles HP, Martinez CAR, Priolli DG, Waisberg J: Gastric iron foreign body. Arq Med ABC 2004;29:63-66. 
15 Quercioli A, Dallegri F, Ottonello L, Montecucco F, Borgonovo G: Intestinal radiation-induced stricture favours small bowel obstruction by phytobezoar: report of a case. Gastroenterol Res Pract 2009;2009:482039.

16 Ghosheh B, Salameh JR: Laparoscopic approach to acute small bowel obstruction: review of 1,061 cases. Surg Endosc 2007;21:1945-1949.

17 Gaya J, Barranco L, Llompart A, Reyes J, Obrador A: Persimmon bezoars: a successful combined therapy. Gastrointest Endosc 2002;55:581-583.

-18 Krausz MM, Moriel EZ, Ayalon A, Pode D, Durst AL: Surgical aspects of gastrointestinal persimmon phytobezoar treatment. Am J Surg 1986;152:526-530.

19 Tayeb M, Khan FM, Rauf F, Khan MM: Phytobezoar in a jejunal diverticulum as a cause of small bowel obstruction: a case report. J Med Case Rep 2011;5:482.

20 Chisholm EM, Leong HT, Chung SC, Li AK: Phytobezoar: an uncommon cause of small bowel obstruction. Ann R Coll Surg Engl 1992;74:342-344.

21 Debakey M, Oschner A: Bezoars and concretions, comprehensive review of literature with analysis of 303 collected cases and presentation of 8 additional cases. Surgery 1939;5:132-160.

22 Kaushik NK, Sharma YP, Negi A, Jaswa A: Gastric trichobezoar. Ind J Radiol Imag 1999;9:137-139.

23 Saeed ZA, Rabassa AA, Anand BS: An endoscopic method for removal of duodenal phytobezoars. Gastrointest Endosc 1995;41:74-76.

24 Roy M, Fendrich I, Li J, Szomstein S, Rosenthal RJ: Treatment option in patient presenting with small bowel obstruction from phytobezoar at the jejunojejunal anastomosis after Roux-en-Y gastric bypass. Surg Laparosc Endosc Percutan Tech 2012;22:e243-e245.

-25 Robles R, Parrilla P, Escamilla C, Lujan JA, Torralba JA, Liron R, Moreno A: Gastrointestinal bezoars. Br J Surg 1994;81:1000-1001.

-26 Ahn YH, Maturu P, Steinheber FU, Goldman JM: Association of diabetes mellitus with gastric bezoar formation. Arch Intern Med 1987;147:527-528.

-27 Ripollés T, García-Aguayo J, Martínez MJ, Gil P: Gastrointestinal bezoars: sonographic and CT characteristics. AJR Am J Roentgenol 2001;177:65-69.

-28 Yildirim T, Yildirim S, Barutcu 0, Oguzkurt L, Noyan T: Small bowel obstruction due to phytobezoar: CT diagnosis. Eur Radiol 2002;12:2659-2661.

29 Kim JH, Ha HK, Sohn MJ, Kim AY, Kim TK, Kim PN, Lee MG, Myung SJ, Yang SK, Jung HY, Kim JH: CT findings of phytobezoar associated with small bowel obstruction. Eur Radiol 2003;13:299-304

-30 Rodicio JL, Bongera M, Abdel-Lah O, Hevia I, Alonso B, Herrero M, Martínez M, Vega Á, Ayala JM, Pozo F: Gastroduodenal phytobezoar treated with Coca-Cola ${ }^{\circledR}$. Rev Esp Enferm Dig 2012;104:101-102.

-31 Ladas SD, Triantafyllou K, Tzathas C, Tassios P, Rokkas T, Raptis SA: Gastric phytobezoars may be treated by nasogastric Coca-Cola lavage. Eur J Gastroenterol Hepatol 2002;14:801-803.

32 de Menezes Ettinger JE, Silva Reis JM, de Souza EL, Filho Ede M, Galvão do Amaral PC, Ettinger E Jr, Fahel E: Laparoscopic management of intestinal obstruction due to phytobezoar. JSLS 2007;11:168-171. 